\title{
Analisis Pengaruh Port Of Destination, Tonase Dan Durasi Plak Pelabuhan Terhadap Besarnya Biaya Ekspor (Studi Kasus Pada "PT. Sukses Lautan Indonesia")
}

\author{
Mariya Ulva ${ }^{1}$, Darno ${ }^{2}$ \\ Fakultas Ekonomi \\ Universitas Maarif Hasyim Latif, Sidoarjo, Indonesia \\ mariyaulva04@gmail.com ${ }^{1}, \underline{\text { darno@dosen.umaha.ac.id }}{ }^{2}$
}

\section{ARTICLE INFO}

\section{Article History}

Received : 29 Oktober 2019

Reviewed : 15 Oktober 2019

Published : 31 Oktober 2019

Available Online : 2 November 2019

\section{Keywords}

Prosedur Ekspor,

Biaya Ekspor,

Port Of Destination,

Tonase,

Plak Pelabuhan

\begin{abstract}
Penelitian ini bertujuan untuk mengetahui apakah faktor jarak tujuan Negara (Port Of Destination), jumlah barang yang di ekspor (tonase) dan durasi penumpukan container (Plak Pelabuhan) berpengaruh terhadap besarnya biaya ekspor yang ada di PT. Sukses Lautan Indonesia. Penelitian ini menggunakan pendekatan kuantitatif. Data yang digunakan adalah data primer dan sekunder. Pengambilan data primer dilakukan dengan cara wawancara kepada pihak internal perusahaan. Pengambilan data sekunder berasal dari laporan keuangan perusahaan, buku, artikel, internet maupun instansi-instansi lain yang terkait seperti perpustakaan.

Teknik analisis menggunakan regresi linier berganda dengan bantuan aplikasi SPSS versi 24. Sampel yang digunakan dalam penelitian ini berjumlah 90 data ekspor yang sudah dilakukan di PT. Sukses Lautan Indonesia dari tahun 20162017.

Hasil penelitian menunjukkan bahwa faktor jarak tujuan Negara (port Of destination), dan durasi penumpukan container (plak pelabuhan) dalam uji statistik masing-masing berpengaruh positif dan signifikan terhadap besarnya biaya ekspor. Sedangkan, faktor jumlah barang yang di ekspor (tonase) tidak berpengaruh signifikan terhadap besarnya biaya ekspor yang ada di PT. Sukses Lautan Indonesia. Jarak tujuan pengiriman (port of destination), jumlah barang yang diekspor (tonase) dan durasi penumpukan container (plak pelabuhan) mempengaruhi biaya ekspor sebesar 90,5\% dan 9,5\% dipengaruhi oleh variabel lain di luar yang terdapat pada penelitian ini.
\end{abstract}

\section{PENDAHULUAN}

Indonesia merupakan Negara kepulauan terbesar di dunia, aspek kelautan dan kemaritiman dapat menjadi tema utama dalam pembangunan nasional terutama memanfaatkan potensi hasil laut untuk kesejahteraan masyarakat Indonesia.

Kegiatan ekspor barang merupakan sistem perdagangan yang memungkinkan seseorang mengadakan trading lintas negara. Saat ini pemerintah berupaya meningkatkan devisa dengan menggenjot arus ekspor barang. Prosedur ekspor sebenarnya lebih mudah daripada kegiatan prosedur impor karena saat ini lebih banyak aturan yang mengatur tentang impor dari pada tentang ekspor, terutama untuk masalah pembayaran pajak.

Komponen biaya ekspor merupakan salah satu tujuan untuk memperluas pasar mendapatkan harga jual yang lebih baik. Setiap perusahaan yang bergerak dibidang usaha bisnis, memiliki tujuan yang sama yaitu memperoleh laba untuk dapat mempertahankan bisnisnya. Misalnya dengan meminimalisir biaya eskpor perusahaan bisa meningkatkan besarnya laba.

Waktu tempuh, jarak perjalanan dan waktu operasi akan bepengaruh terhadap biaya transportasi. Ketiganya berbanding lurus, semakin besar waktu tempuh, jarak dan waktu operasi, semakin tinggi pula biayanya, (Purnomo, 2010).

Efisiensi dan waktu pengiriman serta biaya transportasi pada kasus tertentu bisa memberikan kontribusi 50\% dari total biaya logistik perusahaan (Srivastava dan Benton, 1990). Rute terpendek pengiriman akan 
mengurangi biaya pengiriman (Hamada, 2016). Biaya kirim barang dipengaruhi oleh rute pengiriman dan kapasitas angkut (berat dan volume) (Bektas, 2006).

PT. Sukses Lautan Indonesia merupakan sebuah perusahaan yang bergerak di bidang ekspor perikanan. Transaksi ekspor dilakukan ke berbagai negara seperti Malaysia, Vietnam, Thailand, USA, Italy dan China yang merupakan komoditi ekspor terbesar. Untuk negara tujuan ekspor mempunyai syarat dan ketentuan yang berbeda-beda. Dalam melakukan kegitan ekspor, perusahaan ini memakai bantuan jasa PPJK (Pengusaha Pengurusan Jasa Kepabeanan) yaitu suatu badan usaha yang melakukan kegiatan pengurusan pemenuhan kewajiban pabean untuk atas nama eksportir maupun importir dalam proses pembuatan PEB (Pemberitahuan Ekspor Barang) dan jasa Freight Forwading atau EMKL (Ekspedisi Muatan Kapal Laut).

Berdasarkan hal-hal yang diuraikan di atas, maka penulis memandang perlu untuk menguraikan komponen biaya yang diperlukan untuk kegiatan ekspor barang yang dilakukan di PT. Sukses Lautan Indonesia sebagai perusahaan yang berdiri di bidang ekspor perikanan.

\section{Tipe Artikel}

Penelitian ini dilakukan berdasarkan beberapa referensi penelitian terdahulu diantaranya Faktor-Faktor yang Mempengaruhi Ekspor Cengkeh di Indonesia tahun 2001-2011, Sulthan, Universitas Hasanuddin Makassar, 2014 menggunakan analisis statistika persamaan linier berganda untuk mengetahui permintaan ekspor dan faktor-faktor yang mempengaruhi permintaan ekspor cengkeh. Analisis ekspor kopi Indonesia, Ramadhani, Universitas Islam Indonesia Yogyakarta, 2018 menggunakan analisis ekonometrika dengan menggunakan metode data panel dan bantuan software Eviews 9.0. Penelitian ini menggunakan variable volume ekspor kopi Indonesia, data GDP (Gross Dosmetic Product) riil negara tujuan, nilai tukar rupiah terhadap mata uang negara tujuan eskpor, harga kopi Internasional, dan harga kopi domestik negara tujuan.

\section{METODE PENELITIAN}

Penelitian ini menggunakan metode kuantitatif dengan menggunakan data primer dan sekunder. Teknik analisis menggunakan regresi linier berganda dengan bantuan SPSS versi 24. Adapun variabel yang di pakai adalah port of destination, tonase dan durasi plak pelabuhan. Port of destination adalah jarak tempuh pengiriman barang dalam satu negara yang sama tetapi berbeda pelabuhan. Tonase adalah berat barang yang akan di kirim atau kapasitas barang yang akan di kiri untuk negara tujuan eksport yang sama. Sedangkan plak pelabuhan adalah durasi waktu oparasi pelabuhan untuk mengirimkan barang eksport ke negara tujuan. Durasi plak di pelabuhan ini akan berpengaruh terhadap frekuensi pengiriman barang dari pelabuhan tersebut ke pelabuhan negara tujuan eksport.

\subsection{Teknik Pengumpulan Data}

Data primer diambil langsung dari tempat penelitian melalui pengamatan langsung, pencatatan dan wawancara secara mendalam (in-depth interview). Wawancara ini dilakukan sebanyak dua kali untuk mengetahui faktor-faktor strategis yang mempengaruhi perusahaan dan menilai sejauh mana perusahaan mampu memberikan respon. Wawancara pihak internal dilakukan dengan direktur utama, kepala bagian produksi dan quality control, kepala bagian keuangan dan administrasi, bagian ekspor serta karyawan dari perusahaan. Kegiatan tersebut bertujuan untuk mengetahui gambaran umum dan sistem perusahaan, produksi yang dilakukan perusahaan, kondisi keuangan perusahaan serta kegiatan operasional perusahaan. Sedangkan wawancara dengan pihak eksternal dilakukan dengan supplier forwading.

Data sekunder yang digunakan berasal dari laporan keuangan perusahaan, buku, artikel, internet maupun instansi-instansi lain yang terkait seperti perpustakaan.

\section{HASIL DAN PEMBAHASAN}

Hubungan antara variabel independen yaitu variabel jarak tujuan pengiriman (port of destination), jumlah barang yang diekspor (tonase), dan durasi penumpukan container (plak pelabuhan) terhadap variabel dependen yaitu biaya pengiriman dapat diketahui dengan menggunakan model regresi linier berganda. 
Keterangan Biaya Penumpukan

\begin{tabular}{|l|r|}
\hline $\operatorname{Rp} 1.950 .000,00$ & 1 \\
\hline $\operatorname{Rp} 2.600 .000,00$ & 2 \\
\hline $\operatorname{Rp} 3.250 .000,00$ & 3 \\
\hline $\operatorname{Rp} 3.900 .000,00$ & 4 \\
\hline $\operatorname{Rp} 5.150 .000,00$ & 5 \\
\hline
\end{tabular}

Keterangan berdasarkan jarak

\begin{tabular}{|l|l|}
\hline XIAMEN & $(3578 \mathrm{KM})$ \\
\hline FUZHOU & $(3761 \mathrm{KM})$ \\
\hline BAOMAN & $(4436 \mathrm{KM})$ \\
\hline
\end{tabular}

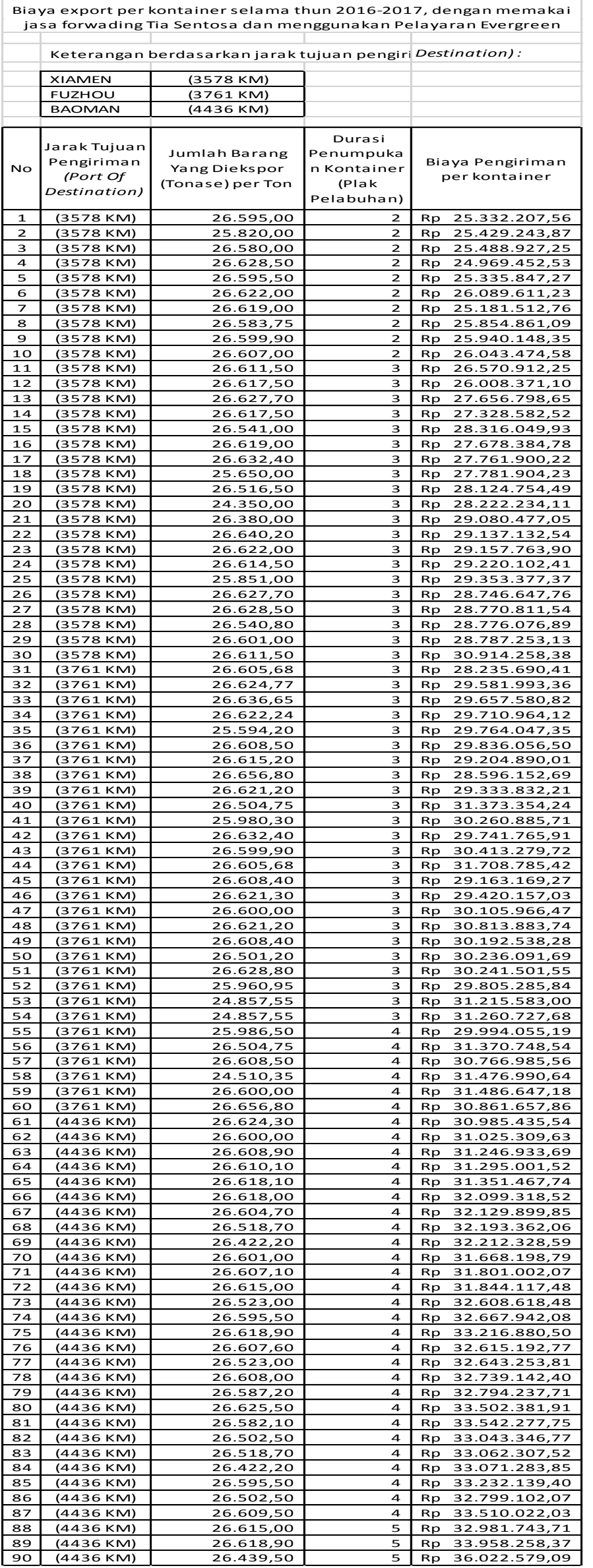


Data yang tersedia untuk membuktikan hipotesis akan dijelaskan dalam perhitungan serta pengujianpengujian terhadap masing-masing koefisien regresi yang diperoleh dengan menggunakan alat bantu komputer menggunakan program SPSS 24.

\subsection{INTERPRETASI MODEL}

Berdasarkan pengolahan data dengan menggunakan program computer SPSS 24 diperoleh hasil sebagai berikut:

Tabel 1 Tabel Koefesiensi

\begin{tabular}{|c|c|c|c|}
\hline \multirow{2}{*}{ Model } & \multicolumn{2}{|c|}{$\begin{array}{l}\text { Unstandardized } \\
\text { Coefficients }\end{array}$} & \multirow{2}{*}{\begin{tabular}{|c|}
$\begin{array}{c}\text { Standardized } \\
\text { Coefficients }\end{array}$ \\
Beta
\end{tabular}} \\
\hline & B & Std. Error & \\
\hline (Constant) & 19526872.480 & 6634363.717 & \\
\hline $\begin{array}{l}\text { Jarak Tujuan Negara } \\
\text { (Port of Destination) }\end{array}$ & 1682.469 & 529.718 & 0.256 \\
\hline $\begin{array}{l}\text { Jumlah barang yang di } \\
\text { ekspor } \\
\text { (Tonase) }\end{array}$ & -144.933 & 254.506 & -0.027 \\
\hline $\begin{array}{l}\text { Durasi penumpukan } \\
\text { container } \\
\text { (Plak Pelabuhan) }\end{array}$ & 2340916.476 & 271990.142 & 0.687 \\
\hline
\end{tabular}

Berdasarkan rumusan model persamaan yang ada, maka dapat dituliskan model persamaan sebagai berikut:

$\mathrm{Y}=\beta 0+\beta 1 \mathrm{X} 1+\beta 2 \mathrm{X} 2+\beta 3 \mathrm{X} 3$

$\mathrm{Y}=19526872+1682 \mathrm{X} 1-145 \mathrm{X} 2+2340916 \mathrm{X} 3$

Maka dapat dinyatakan kesimpulan sebagai berikut :

a) Konstanta $(\alpha)$, pada persamaan nilai konstanta sebesar 19526872 yang menunjukan bahwa jika masingmasing variabel bebas (X1, X2, X3) konstan atau tidak mengalami perubahan selama periode penelitian, maka akan tetap terjadi peningkatan volume ekspor sebesar 19526872 persen per tahun.

b) Variabel jarak tujuan pengiriman atau port of destination (X1) memiliki nilai koefisien regresi yang positif yaitu sebesar 1682,469. Nilai koefisien positif menunjukkan bahwa terdapat pengaruh positif dan signifikan atas jarak tujuan pengiriman atau port of destination terhadap biaya pengiriman. Hal ini menggambarkan bahwa jika terjadi kenaikan Jarak sebesar 1 satuan, maka biaya pengiriman akan mengalami peningkatan sebesar 1682,469 satuan, dengan asumsi variabel independen yang lain dianggap konstan artinya, jarak tujuan pengiriman (port of destination) berpangaruh positif dan signifikan terhadap biaya ekspor.

c) Variabel jumlah barang yang diekspor atau tonase (X2) memiliki nilai koefisien regresi yang negatif yaitu sebesar -144.933. Nilai koefisien negatif menunjukkan bahwa terdapat pengaruh negatif atas jumlah ekspor terhadap biaya pengiriman. Halini menggambarkan bahwa jika terjadi kenaikan harga sebesar 1 satuan, maka jumlah biaya pengiriman akan mengalami penurunan sebesar 144.933 satuan, dengan asumsi variabel independen yang lain dianggap konstan. Dalam hal ini dapat disimpulkan bahwa jumlah barang yang di ekspor (tonase) tidak mempengaruhi biaya ekspor.

d) Variabel durasi penumpukan container atau plak pelabuhan (X3) memiliki nilai koefisien regresi yang positif yaitu sebesar 2340916.476. Nilai koefisien positif menunjukkan bahwa Durasi penumpukan container terhadap biaya pengiriman berpengaruh positif. Hal ini menggambarkan bahwa jika terjadi kenaikan durasi pengirimansebesar 1 satuan, maka volume ekspor cengkeh Indonesia akan mengalami 
peningkatan sebesar 2340916.476 satuan, dengan asumsi variabel independen yang lain dianggap konstan. Yang artinlya, variabel durasi penumpukan container (plak pelabuhan) berpengaruh terhadap besarnya biaya ekspor.

\subsection{UJI NORMALITAS}

Uji normalitas bertujuan untuk menguji data variabel independen dan variabel dependen keduanya berdistribusi normal atau tidak.

Gambar 1.1 Grafik Uji Normalitas

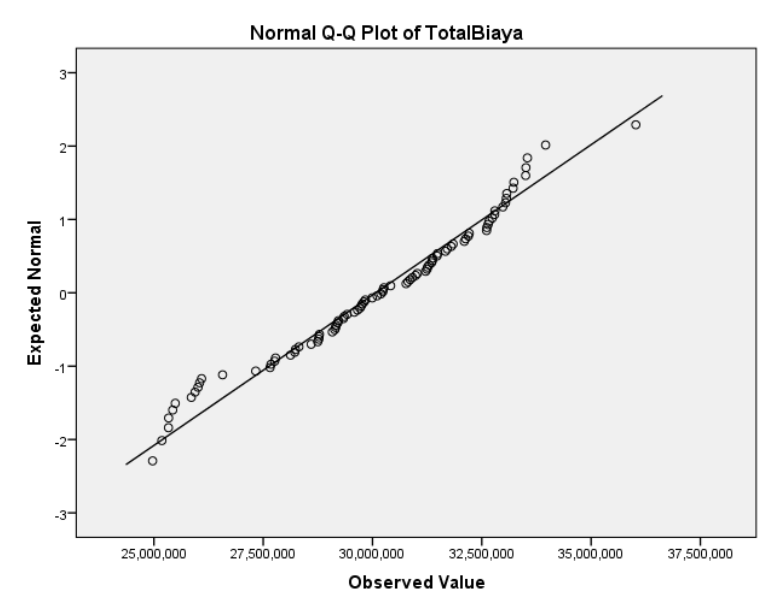

Berdasarkan hasil metode grafik Uji Normalitas pada gambar hasil regresi menunjukkan bahwa data terdistribusi secara normal karena data berada di sekitar dan mengikuti garis diagonal.

\section{UJI F}

Uji F dilakukan untuk melihat pengaruh variabel bebas secara bersama-sama terhadap variabel tidak bebas

Tabel 2. Tabel Uji F

\begin{tabular}{|c|c|c|c|c|c|c|}
\hline \multicolumn{2}{|c|}{ Model } & $\begin{array}{c}\text { Sum of } \\
\text { Squares }\end{array}$ & df & Mean Square & F & Sig. \\
\hline \multirow{4}{*}{1} & Regression & $\begin{array}{c}43409512960 \\
0000.000\end{array}$ & 3 & $\begin{array}{c}14469837650 \\
0000.000\end{array}$ & 129.816 & 0.000 \\
\cline { 2 - 7 } & Residual & $\begin{array}{c}95859285490 \\
000.000\end{array}$ & 86 & $\begin{array}{c}11146428540 \\
00.000\end{array}$ & & \\
\cline { 2 - 7 } & Total & $\begin{array}{c}52995441510 \\
0000.000\end{array}$ & 89 & & & \\
\hline
\end{tabular}

Hipotesis Berbunyi:

$$
\begin{aligned}
& \mathrm{H} 0: \beta_{1}=\beta_{2}=\beta 3=0, \\
& \mathrm{H} 1: \beta_{1} \neq \beta_{2} \neq \beta 3 \neq 0,
\end{aligned}
$$

Pada tabel diatas menunjukkan angka hasil uji $\mathrm{F}$ menghasilkan $\mathrm{F}$ hitung sebesar 129.816. Sementara itu nilai pada tabel distribusi nilai $\mathrm{F}$ pada taraf signifikansi 5\% adalah df: $\alpha,(\mathrm{k}-1),(\mathrm{n}-\mathrm{k})=0,10,(4-1),(90-4)=$ 2.71. Oleh karena F hitung 129.816> F table 2.71 dan dan nilai signifikansinya lebih kecil dari $\alpha(0.000<0.05)$ maka $\mathrm{H} 1$ diterima dan $\mathrm{H} 0$ ditolak, artinya antara variable jarak tujuan pengiriman atau port of destination 
(X1), Jumlah barang yang diekspor atau tonase (X2), durasi penumpukan container atau plak pelabuhan (X3). memiliki pengaruh signifikan bersama-sama terhadap biaya ekspor.

\section{UJI T}

Uji t dilakukan untuk mengetahui pengaruh masing-masing variabel independen terhadap variable dependen.

Tabel 3. Uji t Variabel

\begin{tabular}{|l|c|c|c|c|c|}
\hline \multirow{2}{*}{ Model } & $\mathrm{t}$ & Sig. & \multicolumn{3}{c|}{ Correlations } \\
\cline { 2 - 6 } & & & Zero-order & Partial & Part \\
\hline (Constant) & 2.943 & 0.004 & & & \\
\hline $\begin{array}{l}\text { Jarak Tujuan } \\
\text { Pengiriman (Port Of } \\
\text { Destination) }\end{array}$ & 3.176 & 0.002 & 0.813 & 0.324 & 0.146 \\
\hline $\begin{array}{l}\text { Jumlah Barang Yang } \\
\text { di Ekspor (Tonase) }\end{array}$ & -0.569 & 0.571 & 0.100 & -0.061 & - \\
\hline $\begin{array}{l}\text { Durasi Penumpukan } \\
\text { Container (Plak } \\
\text { Pelabuhan) }\end{array}$ & 8.607 & 0.000 & 0.893 & 0.680 & 0.395 \\
\hline
\end{tabular}

Berdasarkan hasil olah data dengan menggunakan SPSS, maka diperoleh pemaparan sebagai berikut:

a) Variabel jarak tujuan pengiriman atau port of destination (X1) mendapatkan statistik uji $t=3.176$ dengan signifikansi 0,002. Untuk t-hitung yang dihasilkan adalah positif sebesar 3.176 sedangkan $t$ tabelnya adalah df: $\alpha,(\mathrm{n}-\mathrm{k}),=0,10,(90-4)=1,987$. Karena nilai $\mathrm{t}$ hitung lebih besar dari $\mathrm{t}$ tabel $(3.176>1,987)$ dan nilai signifikansinya lebih kecil dari $\alpha(0.002<0.05)$, maka dapat disimpulkan bahwa Jarak tujuan pengiriman atau port of destination berpengaruh positif dan signifikan mempengaruhi biaya ekspor.

b) Variabel jumlah barang yang diekspor atau tonase (X2) mendapatkan statistik uji $\mathrm{t}=-0.569$ dengan signifikansi 0,571 . Untuk t hitung yang dihasilkan adalah negatif sebesar-0.569sedangkan $t$ tabelnya adalah df: $\alpha,(\mathrm{n}-\mathrm{k}),=0,10,(90-4)=1,987$. Karena nilai $\mathrm{t}$ hitung kurang dari t tabel $(-0.569<1,987)$ dan nilai signifikansinya lebih besar dari $\alpha(0.571>0.05)$, maka dapat disimpulkan bahwa jumlah barang yang diekspor atau tonase berpengaruh negatif dan tidak berpengaruh signifikan terhadap biaya ekspor.

c) Variabel durasi penumpukan container atau plak pelabuhan (X3) mendapatkan statistik uji $\mathrm{t}=$ 8.607dengan signifikansi 0,000 . Untuk t hitung yang dihasilkan adalah positif sebesar 8.607 sedangkan $\mathrm{t}$ tabelnya adalah df: $\alpha,(\mathrm{n}-\mathrm{k}),=0,05,(90-4)=1,987$. Karena nilai $\mathrm{t}$ hitung lebih besar dari $\mathrm{t}$ tabel $(8,607>1,987)$ dan nilai signifikansinya lebih kecil dari $\alpha(0.000<0.05)$, maka dapat disimpulkan bahwa durasi penumpukan container atau plak pelabuhn berpengaruh positif dan signifikan mempengaruhi biaya ekspor.

\section{UJI KOEFISIEN KORELASI (R)}

Koefisien korelasi merupakan nilai hasil dari metode statistik yang digunakan untuk meguji ada atau tidaknya hubungan serta arah hubungan dari dua variabel atau lebih. Nilai R terletak antara -1 sampai dengan $1(-1 \leq \mathrm{R} \leq 1)$. 
Tabel 4. Nilai Koefisien Regresi

\begin{tabular}{|l|c|l|l|l|}
\hline \multicolumn{5}{|c|}{ Model Summary } \\
\hline Model & $\mathrm{R}$ & $\mathrm{R}$ Square & $\begin{array}{c}\text { Adjusted R } \\
\text { Square }\end{array}$ & $\begin{array}{c}\text { Std. Error of the } \\
\text { Estimate }\end{array}$ \\
\hline 1 & 0.905 & 0.819 & .813 & 1055766.47700 \\
\hline \multicolumn{5}{|c|}{} \\
$\begin{array}{l}\text { a. Predictors: (Constant), Durasi Penumpukan Container (Plak } \\
\text { Pelabuhan), Jumlah Barang Yang Di Ekspor (tonase), Jarak } \\
\text { Tujuan Pengiriman (Port Of Destination) }\end{array}$ \\
\hline
\end{tabular}

Dari tabel di atas dapat diketahui bahwa nilai $\mathrm{R}(\mathrm{R})$ adalah 0,905 . Hal ini menunjukkan bahwa korelasi antara variabel independen yang terdiri variable jarak tujuan pengiriman atau port of destination (X1), Jumlah barang yang diekspor atau tonase (X2), durasi penumpukan container atau plak pelabuhan (X3) terhadap biaya ekspor sebesar 90,5\%. Di samping itu, dengan nilai 0,905 yang mendekat ke arah positif 1 berarti hubungan variabel-variabel bisa dikatakan kuat.

\section{UJI KOEFISIEN DETERMINASI (R2)}

Koefisen determinasi digunakan untuk mengetahui keeratan hubungan antara variabel bebas dengan variabel terikat. Nilai R2 terletak antara 0 sampai dengan $1(0 \leq \mathrm{R} 2 \leq 1)$. Tujuan menghitung koefisien determinasi adalah untuk mengetahui seberapa besar pengaruh variabel bebas terhadap variabel terikat.

Dari tabel 4 di atas, dapat diketahui bahwa nilai $R$ Square $\left(R^{2}\right)$ adalah 0,819 . Hal ini menunjukkan bahwa sebesar 81,9\% Biaya ekspor ditentukan oleh variasi dari variable jarak tujuan pengiriman atau port of destination (X1), jumlah barang yang diekspor atau tonase (X2), Durasi penumpukan container atau plak pelabuhan (X3). Sedangkan sisanya sebesar 18,1\% dipengaruhioleh faktor-faktor lain di luar model penelitian. Dengan demikian, hubungan variabel-variabel bisa dikatakan kuat.

\section{KESIMPULAN}

Berdasarkan penelitian yang telah dilakukan mengenai analisis regresi linier berganda yang telah dijabarkan sebelumnya diperoleh beberapa kesimpulan sebagai berikut:

a) Hasil analisis menunjukkan bahwa jarak tujuan pengiriman (port of destination) dalam uji statistik mendapatkan nilai 3,176 dengan signifikansi 0,002 lebih kecil dari $\alpha(0,002<0,05)$ yang artinya berpengaruh positif terhadap biaya ekspor secara signifikan.

b) Hasil analisis menunjukkan bahwa jumlah barang yang diekspor (tonase) dalam uji statistik mendapatkan nilai $-0,569$ dengan signifikansi 0,571 lebih besar dari $\alpha(0,571>0,05)$ yang artinya berpengaruh negatif dan tidak berpengaruh signifikan terhadap biaya ekspor.

c) Hasil analisis menunjukkan bahwa durasi penumpukan container (plak pelabuhan) dalam uji statistik mendapatkan nilai 8,607 dengan signifikansi 0,000 lebih kecil dari $\alpha(0,000<0,05)$ yang artinya berpengaruh positif terhadap biaya ekspor secara signifikan.

d) Jarak tujuan pengiriman (port of destination) dan durasi penumpukan container (plak pelabuhan) masingmasing berpengaruh besar terhadap biaya pengiriman, tetapi jumlah barang yang diekspor (tonase) tidak berpengaruh penting pada biaya ekspor.

e) Jarak tujuan pengiriman (port of destination), jumlah barang yang diekspor (tonase) dan durasi penumpukan container (plak pelabuhan) mempengaruhi biaya ekspor sebesar 90,5\% dan 9,5\% dipengaruhi oleh variabel lain di luar yang terdapat pada penelitian ini. 


\section{SARAN}

Berdasarkan hasil penelitian yang dilakukan, saran yang dapat peneliti berikan kepada PT. Sukses Lautan Indonesia yang berkaitan dengan biaya ekspor adalah sebagai berikut:

a) Dapat dilihat terdapat 9,5\% variabel-variabel lain yang mempengaruhi biaya ekspor, sehingga untuk penelitian selanjutnya diharapkan bisa menambah variabel-variabel tersebut sehingga diperoleh model baru yang lebih baik.

b) Sebelum melakukan kegiatan ekspor, pada saat booking space di pelayaran seharusnya perusahaan terlebih dahulu memastikan schedule kapal dan memperkirakan bahwa schedule kapal tidak akan delay terlalu banyak dari tanggal yang sudah ditetapkan. Dengan begitu, perusahaan dapat meminimalisir biaya penumpukan container ekspor (plak pelabuhan) yang disebabkan oleh delay kapal.

c) Meskipun jumlah barang yang diekspor (tonase) tidak berpengaruh positif dan signifikan akan tetapi lebih baik pada saat melakukan stuffing, seharusnya dipastikan terlebih dahulu bahwa barang yang akan dimuat tidak melebihi tare container (berat kotor container). Karena, apabila container kelebihan muatan (over), maka container tidak bisa masuk dipelabuhan dan perusahaan tidak bias melakukan ekspor.

\section{DAFTAR PUSTAKA}

[1] Asri, Itsna Khoirotul. 2005. Evaluasi Sistim Pengendalian Internal Penjualan Ekspor dan Penerimaan Kas Pada CV. Suka Lentera Abadi Banyudono Boyolali. Laporan tugas akhir. Universitas Sebelas Maret Surakarta.

[2] Bektas, T. (2006). The multiple travelling salesman problem: an overview of formulations and solution procedures. The International Journal of Management Science vol. 34, no. 3, 209-219.

[3] Haikal \& Hamdani. 2018, Seluk Beluk Perdagangan Ekspor Impor Jilid 1(Satu). Jakarta, Bushindo.

[4] Hamada, Muryastuti, dkk, 2018, Analisis Penentuan Rute Terbaik Menggunakan Shortest Route Problem dengan Metode UNSY untuk Meminimalisir Biaya Transportasi. Performa (2016) Vol. 15, No.1: 1-9, UNS, Solo.

[5] Handayani, Fitria Kusumo. 2011. Analisis Prosedur Pengiriman Barang Pada PT. Glopack Packaging. Laporan tugas akhir. Politeknik Negeri Batam.

[6] Isma, Listia Nur. 2012. Analisis Strategi Bisnis Ekspor Pembekuan Ikan (Studi Kasus: PD SAMBU di Komplek Pelabuhan Perikanan Nusantara (PPN) Kejawanan, Cirebon, Jawa Barat). Skripsi. Institut Pertanian Bogor.

[7] Keputusan Menteri Keuangan Republik Indonesia Nomor 557/KMK.04/2002 tentang Tatalaksana Kepabeanan Di Bidang Ekspor.

[8] Peraturan Menteri Keuangan Nomor 13/PMK.010/2017 tentang Penetapan Barang Ekspor yang Dikenakan Bea Keluar dan Tarif Bea Keluar.

[9] Peraturan Direktur Jenderal Bea dan Cukai Nomor PER-32/BC/2014 jo. PER-29/BC/2016 tentang Tata Laksana Kepabeanan di Bidang Ekspor.

[10] Peraturan Direktur Jenderal Bea dan Cukai Nomor P-41/BC/2008 jo. P-07/BC/2009 jo. PER-18/BC/2012 jo. PER-34/BC/2016 tentang Pemberitahuan Pabean Ekspor.

[11] Peraturan Menteri Keuangan Nomor No. 145/PMK.04/2007 jo. PMK No. 148/PMK.04/2011 jo. PMK No. 145/PMK.04/2014 tentang Ketentuan Kepabeanan di Bidang Ekspor.

[12] Peraturan Menteri Keuangan Nomor 214/PMK.04/2008 jo. PMK No. 146/PMK.04/2014 jo. PMK No. 86/PMK.04/2016 tentang Pemungutan Bea Keluar.

[13] Peraturan Menteri Keuangan Nomor 224/PMK.04/2015 tentang Pengawasan Terhadap Impor atau Ekspor Barang 
[14] Peraturan Menteri Perdagangan Republik Indonesia Nomor 13 Tahun 2012 Tentang Ketentuan Umum Di Bidang Ekspor.

[15] Peraturan Pemerintah No. 121 Tahun 2018 Tentang Perubahan Atas Peraturan Menteri Perhubungan Nomor PM 72 Tahun 2017 Tentang Jenis, Struktur, Golongan Dan Mekanisme Penetapan Tarif Jasa Kepelabuhan

[16] Peraturan Pemerintah Republik Indonesia Nomor 24 Tahun 2018 Tentang Pelayanan Perizinan Berusaha Terintegrasi Secara Elektronik.

[17] Priyanto, Joko. 2009. Evaluasi Sistem Dan Prosedur Penjualan Ekspor Pada Pt. Mondrian. Laporan tugas akhir. Universitas Sebelas Maret.

[18] Purnomo, Agus. 2010. Penentuan Rute Pengiriman dan Biaya Transportasi Dengan Menggunakan Metode Clark and Wright Saving Heuristic (Studi Kasus di PT. Teh Botol Sosro Bandung) Logistik Bisnis Politeknik Pos Indonesia, Volume 1, Nomor 2, November 2010.

[19] Putra, Dinan Arya. 2013. Analisis Faktor-faktor Yang Mempengaruhi Ekspor Tembakau Indonesia Ke Jerman. Skripsi. Universitas Negeri Semarang.

[20] Rahmi, Fauzian Akmal. 2018. Analisis Keunggulan Komparatif dan Determinan Ekspor Ikan Tuna Indonesia Ke Jepang, Amerika Serikat, dan Thailand. Skripsi. Universitas Airlangga.

[21] Ramadhani, Riska. 2018. Analisis Ekspor Kopi Indonesia. Skripsi. Universitas Islam Indonesia Yogyakarta.

[22] Srivastava, R. and Benton, W.C. (1990). The location routing problem: Considerations in physical distribution system. Computers and Operations Research, vol. 17, no. 5, pp. 427-435.

[23] Septiani, Faradhilla. 2010. Prosedur Dokumen Ekspor Pada PT. Arindo Jaya Mandiri (Studi Kasus Pada PT. Arindo Jaya Mandiri Semarang). Laporan tugas akhir. Universitas Sebelas Maret Surakarta.

[24] SK Menteri Perindustrian dan Perdagangan SK No. 558/MPP/KEP/12/1998, SK No. 17/MDAG/per/9/2005, SK No. 43/M-DAG/per/10/2007

[25] Sulthan. 2014. Analisis Faktor-Faktor Yang Memengaruhi Ekspor Cengkeh Di Indonesia Tahun 2001 2011. Skripsi. Universitas Hasanuddin Makassar.

[26] Tegela, Sinthya. 2011. Analisis China-India (Chindia) Sebagai Negara Maju Di Kawasan Asia. Skripsi. Universitas Hasanuddin Makassar.

[27] Undang- Undang No.10 Tahun 1995 tentang Kepabeanan

[28] Undang-Undang No.17 Tahun 2006 tentang Perubahan

[29] Utama, Mohammad. 2011. Analisis Pendapatan Usaha Pengolahan Fillet Ikan. (Studi Kasus PT. Ojid Kharisma Nusantara pada Tahun 2010). Skripsi. Universitas Islam Negeri Syarif Hidayatullah Jakarta. 